\title{
AMCoR
}

Asahikawa Medical College Repository http://amcor.asahikawa-med.ac.jp/

Pediatrics International (2002) 44(1):55-59.

Fetal growth and the timing of exposure to maternal smoking

Hiroki, Ohmi ; Kenzou, Hirooka ; Yoshikatsu, Mochizuki 


\section{Fetal growth and the timing of exposure to maternal} smoking.

Running title: Fetal growth and maternal smoking

Hiroki Ohmi MD

Health and Disease Prevention Division, Department of Health and Welfare,

Hokkaido Government, N3-W6, Chuo-ku, Sapporo, Hokkaido, 060-8588, Japan.

Kenzou Hirooka MA

Department of Public Health, School of Medicine, Asahikawa Medical

College, 2-1, Midorigaoka-Higashi, Asahikawa, Hokkaido, 078-8510, Japan.

Yoshikatsu Mochizuki DSc

Department of Community Health Nursing, School of Nursing, Asahikawa

Medical College, 2-1, Midorigaoka-Higashi, Asahikawa, Hokkaido,

078-8510, Japan.

Corresponding author: Hiroki Ohmi

Health and Disease Prevention Division, Department of Health and Welfare,

Hokkaido Government, N3-W6, Chuo-ku, Sapporo, Hokkaido, 060-8588, Japan.

phone: +81-11-231-4111 extension: 25-404

facsimile: +81-11-232-8216

e-mail: hiroki.oomi@pref.hokkaido.jp

Number of text pages: 10, reference pages: 2, figure legend: 1 , tables: 3 . 


\begin{abstract}
Background: Maternal smoking during the third trimester reduces birthweight of full-term neonate. We assessed the relationship between the timing of exposure to maternal smoking, gestational period, and weight and body length for both full-term and preterm neonates.
\end{abstract}

Methods: A retrospective study with a questionnaire was conducted in 1,194 infants who participated in the official medical examination for 3-years-old infants.

Results: The risk of preterm birth from mother who smoked during any trimesters was significantly increased. The body length of neonates whose mothers smoked during the third trimester was shorter than that of neonates whose mothers did not smoked during the third trimester. The weight of full-term neonates whose mothers smoked during the third trimester was lighter than that of neonates whose mothers did not smoked during the third trimester.

Conclusions: Maternal smoking during any trimesters increased the risk of preterm birth. Maternal smoking during the third trimester reduced the body length of both full-term and preterm neonates, and the birthweight of the full-term neonate in a somewhat dose dependent manner.

Keywords: fetal growth, maternal smoking, trimester. 


\section{Introduction}

Low birthweight is a major public health problem in both developed and developing countries. There are two categories, one is intrauterine growth retardation, and the other is preterm birth occurring before the 37th week of pregnancy ${ }^{1}$. In developed countries, maternal cigarette smoking during pregnancy is a primary known risk factor for both intrauterine growth retardation and preterm birth ${ }^{1}$. It was clarified that maternal smoking during the third trimester reduced birthweight of full-term neonate ${ }^{2-5}$.

We assessed the relationship between the timing of exposure to maternal smoking and gestational period. The relationship between the timing of maternal smoking, and weight and body length for both full-term and preterm neonates was also assessed. 


\section{Methods}

The subjects were the infants who participated in the official medical examinations for 3-years-old infants, which were provided by municipal health service sections, from 1994 to 1997 at 4 rural towns (Bekkai, Nakashibetsu, Shibetsu and Rausu) in Hokkaido, Japan. We mailed questionnaires containing questions for the 1,720 mothers in the study (age, educational background, smoking and drinking habits during pregnancy) who had 3-years-old infants. Of 1,632 participants, 1,589 questionnaires were collected at the medical examination settings. Thirty-four infants whose mothers drank more than twice a month during pregnancy were excluded in the analysis. We analysed 1,194 singleton infants without malformation whose mothers replied smoking habits during pregnancy. No pregnant case of addiction to illicit drugs was reported in this area. Weight and body length of neonate and gestational period were obtained from medical and health records written by obstetricians and paediatricians in the Maternal and Child Handbooks which were supplied at the registration of pregnancy by municipal authorities.

Mothers were categorised into one of five groups according to their smoking habits by trimester: 
1. Non-smokers: mothers who never smoked and those who stopped smoking prior to pregnancy were combined.

2. Smoked during the first trimester of pregnancy only.

3. Smoked during the first and second trimesters of pregnancy only.

4. Smoked during the first and third trimesters, the second and third trimesters or the third trimester of pregnancy only.

5. Smoked throughout pregnancy.

Mothers were re-categorised into one of five groups according to their smoking habits during the third trimester following Lieberman $\mathrm{et}^{2} \mathrm{al}^{2}$.

1. Non-smokers: mothers who never smoked and those who stopped smoking prior to pregnancy were combined.

2. Smoked during the first and/or second trimester only: mothers who smoked during the first trimester only, the second trimester only or the first and second trimesters only (during the third trimester, they stopped smoking.).

3. Smoked during the third trimester: one to five cigarettes a day, mothers who might also smoke during the first and/or second trimesters.

4. Smoked during the third trimester: six to ten cigarettes a day. 
5. Smoked during the third trimester: over 11 cigarettes a day.

The risk of preterm birth according to smoking category was determined to assess the relationship between the timing of exposure to maternal smoking and gestational period. We also calculated sex-specific standard scores (Z-scores) for weight and body length of neonates for their gestational age, using the growth curve supplied by the Joint Committee of the Japan Paediatric Society and the Japan Society of Obstetrics and Gynaecology for neonate-related terms ${ }^{6}$. To assess the relationship between the timing of exposure to matemal smoking or the smoking habits during the third trimester, and weight and body length of neonates, Z-scores for weight and body length according to smoking categories were compared using one-way analysis of variance followed by two-tailed Bonferroni/Dunn's technique. Neonates were not categorised as being small for dates or appropriate for dates, because the criteria for small for dates was on debate ${ }^{7}$ 


\section{Results}

Young mothers in their twenties showed the highest smoking prevalence. Part-time working mothers were more likely to smoke. Low educational background was associated with a high prevalence of smoking (Table 1). Proportion of preterm birth, and Z scores for weight and body length of neonates were not statistically different among mothers according to their demographic characteristics.

Within the study population, 68 (5.7\%) mothers gave birth to preterm babies. Except for the "smoked first and second trimester only" group which had no preterm birth, the risk of preterm birth from the mother who smoked during any trimesters, even during the first trimester only, was significantly increased (Table 2).

The Z-scores for weight of neonates whose mothers smoked during the first and second trimester only, and smoked throughout pregnancy were less than those of neonates whose mothers never smoked and smoked during the first trimester only. The Z-score for body length of neonate whose mother smoked throughout pregnancy was less than those of neonates whose mothers never smoked and smoked during the first trimester only (Table 3).

Given that smoking during the third trimester seems to reduce weight and body length of neonates, the next step was to examine the influence of amount smoked during the third trimester 
on full-term and preterm neonates. We re-categorised mothers into one of five groups, according to their smoking habits during the third trimester mentioned above. Heavier smokers during the third trimester gave birth to lighter neonates in a somewhat dose dependent manner with full-term births. With preterm births, difference of $\mathrm{Z}$ scores for weight among categories was not statistically significant. Heavy smoking, classified as more than six cigarettes a day, during the third trimester reduced the body length of both full-term and preterm neonates (Fig. 1). A decrease in Z-score for body length with neonates whose mothers smoked over 11 cigarettes a day during third trimester was not statistically significant. 


\section{Discussion}

Our analysis demonstrated that matemal smoking during the third trimester reduced body

length of both full-term and preterm neonates and birthweight of full-term neonate, in a somewhat dose-dependent manner. Because no difference in weight and body length of neonate among matemal demographic characteristics, such as age, education and occupation, was demonstrated in our analysis, smoking habits during the third trimester were suggested to be primary factor to reduce weight and body length of neonates. It might be due to a small sample size that a reduction in birthweight with preterm neonates associated with maternal smoking during the third trimester and that in body length with neonates whose mothers smoked over 11 cigarettes a day during the third trimester were not illustrated statistically. A study with lager sample size is needed to demonstrate the reduction in birthweight associated with maternal smoking with preterm neonate statistically.

A reduction in weight associated with maternal smoking during the third trimester was

illustrated in previous studies ${ }^{2-5}$. Furthermore, our analysis also demonstrated reduction in body length of both full-term and preterm neonates. Taken together with results of the previous studies, it was suggested that the effect of cigarette smoking on intrauterine growth retardation, that is, reduction in body length as well as birthweight, occurred during the third trimester of pregnancy. 
Because maternal smoking during pregnancy is a primary factor accounting for over one-third of all intrauterine growth retardation cases in developed countries ${ }^{1}$, an educational approach for pregnant women to stop smoking before the third trimester might reduce intrauterine growth retardation and related morbidity considerably.

Maternal smoking during pregnancy is a primary factor accounting for nearly $15 \%$ of all preterm birth $^{1}$. In our analysis, no difference in the risk of preterm birth among matemal demographic characteristics was demonstrated, but maternal smoking during pregnancy, even in any trimesters, increased the risk. Smoking cessation during pregnancy would not prevent preterm birth and low weight and short body length subsequent to short gestational period, even if it might be at early stage in pregnancy. Prevention to start smoking or smoking cessation prior to pregnancy is the best way to reduce the adverse consequence of preterm birth associated with exposure to maternal smoking.

Preterm birth and low birthweight predispose infant to respiratory illness, neuro-developmental disorders and later suboptimal health ${ }^{8,9}$. Furthermore, low weight and short body length of neonate hypothesised to be relevant to cardiovascular disease and non-insulin dependent diabetes in adult life ${ }^{10}$. In Japan, however, prevalence of young female smokers is increasing remarkably, although those in developed countries are decreasing ${ }^{11,12}$. In our analysis, 
mothers in their twenties and those with low educational background showed the highest smoking prevalence. To reduce morbidity and mortality related to intrauterine growth retardation and preterm birth, and to offer long-term benefits to offspring, an effective approach to girls and young women to prevent smoking should be strengthened.

We must recognise some potential limitation of our study. First, because smoking history was obtained only from the mother of each infant, we cannot rule out some underreporting of smoking habits ${ }^{5}$. We did not perform measurements of cotinine ${ }^{13}$, a biological marker of smoking, because we were only interested in long-term exposure to tobacco smoke. Because, this area was presumed to be a highly prevalent area of smoking among young women, smoking habits in pregnant women was relatively common ${ }^{14}$. Therefor, few mothers in our study would have a feeling of psychological resistance toward inquiry about smoking habits during pregnancy. Secondly, the number of the mothers incorporated in the analysis was relatively small, especially the numbers of some groups categorised according to smoking habits. Because of not enough data, analysis among subgroups was not adjusted for maternal demographic characteristics. In regards to full-term neonates, the effect of maternal smoking during pregnancy on fetal growth has been well-documented in the world ${ }^{2-5}$ and also in Japan ${ }^{12,15}$. Until now, studies on preterm neonates have been published rarely. In spite of not enough data, our study suggests there is delayed fetal growth 
of preterm neonates, same as that of the full-term neonates due to matemal smoking. We hope that further studies confirming our conclusion would be performed with statistically sufficient data. In spite of these limitations, we believe that our data give further support for health care providers to counsel girls and young women not to start smoking for their offspring as well as for their own health. 


\section{References}

1. Kramer MS. Determinants of low birth weight: Methodological assessment and meta-analysis. Bull World Health Organ 1987; 65: 663-737.

2. Lieberman E, Gremy I, Lang JM, Cohen AP. Low birthweight at term and the timing of fetal exposure to maternal smoking. Am J Public Health 1994; 84: 1127-31.

3. Rush D, Cassano P. Relationship of cigarette smoking and social class to birth weight and perinatal mortality among all births in Britain. J Epidemiol Community Health 1983; 37: 249-55.

4. MacArthur C, Knox EG. Smoking in pregnancy: effects of stopping at different stages. $\mathrm{Br} J$ Obstet Gynaecol 1988; 95: 551-5.

5. Lumley J, Oliver S, Waters E. Intervention for promoting smoking cessation during pregnanccy (Cochrane review). The Cochrane Library, Issue 3. Oxford. 1999.

6. The Joint Committee of the Japan Paediatric Society and the Japan Society of Obstetrics and Gynaecology for neonate-related terms. Recommendation for the neonate-related terms [in Japanese]. J Japan Paediatric Society 1994; 98: 1946-50.

7. Nishida H, Sakamoto S, Sakanoue M. New fetal growth curve for Japanese. Acta Paediatr 
Scand 1985; 319(Suppl.): 62-7.

8. Chard T, Soe A, Costeloe K. The risk of neonatal death and respiratory distress syndrome in relation to birth weight of preterm infants. Am J Perinatol 1997; 14: 523-6.

9. Zubrick SR, Kurinczuk JJ, McDermott BM, McKelvey RS, Silburn SR, Davies LC. Fetal growth and subsequent mental health problems in children aged 4 to 13 years. Dev Med Child Neurol 2000; 42: 14-20.

10. Barker DJ. Fetal origins of cardiovascular disease. Ann Med 1999; 1 (Suppl.): 3-6.

11. Honjo K, and Kawachi I. Effects of market liberalisation on smoking in Japan. Tobacco Control 2000; 9: 193-200.

12. Japan Ministry of Health and Welfare eds. Tobacco and Health Promoting Measure, 2nd edn [in Japanese]. Shakaihoken-kennkyujo, Tokyo, 1996.

13. Boyle P. The hazards of passive- and active-smoking. $N$ Engl J Med. 1993; 328: 1708-9.

14. Survey of Japan Tobacco Industry on smoking prevalence in Japan, 2000. Mainichi Shinbun October, 26, 2000. http://www.mainichi.co.jp/news/selection/archive/200010/26/1027m058-400.html. 
15. Saito R. The smoking habits of pregnant woman and their husbands, and the effect on their infants. [in Japanese] Nippon Koshu Eisei Zassi. 1991; 38: 124-31. 


\section{Figure legend}

Figure 1. Z scores for weight and body length of neonate according to their smoking habits during the third trimester.

Closed circle in each box denotes the median. Limits of the box denote the 25th and 75th percentiles, and the bars denote the 95\% CI. (n) on top of each box and bar denotes the number of the neonates.

One-way analysis of variance followed by two-tailed Bonferroni/Dunn’s technique was used to compare with non-smoking mothers $(*: \mathrm{P}<0.05$, **: $\mathrm{P}<0.01)$, mothers who smoked during the first trimester and/or second trimester only ( $\uparrow: \mathrm{P}<0.01$ ) and mothers who smoked during the third trimester: $1-5$ cigarettes a day ( $\$: \mathrm{P}<0.05)$. 
Table 1. Percentages of smoker during pregnancy, percentages of preterm birth, Z scores for weight and length of neonate among mothers according to their demographic characteristics.

\begin{tabular}{|c|c|c|c|c|c|c|c|c|c|c|}
\hline & \multirow{2}{*}{$\begin{array}{l}\text { No. of } \\
\text { mothers }\end{array}$} & \multicolumn{3}{|c|}{ \%smoker } & \multicolumn{2}{|c|}{ \%preterms } & \multicolumn{2}{|c|}{ Z score for weight (g) } & \multicolumn{2}{|c|}{ Z score for length (cm) } \\
\hline & & $\begin{array}{c}\text { First } \\
\text { trimester }\end{array}$ & $\begin{array}{c}\text { Second } \\
\text { trimester }\end{array}$ & $\begin{array}{c}\text { Third } \\
\text { trimester }\end{array}$ & & (95\%CI) & mean & (95\%CI) & mean & (95\%CI) \\
\hline \multicolumn{11}{|l|}{ Age (years old) } \\
\hline $20-29$ & 421 & 50.1 & 21.9 & 24.0 & 6.9 & (4.7 to 9.7 ) & 0.05 & $(-0.04$ to 0.13$)$ & -0.39 & $(-0.50$ to -0.28$)$ \\
\hline $30-39$ & 729 & 34.7 & 13.7 & 14.5 & 5.2 & (3.7 to 7.1 ) & 0.05 & (-0.01 to 0.12$)$ & -0.33 & $(-0.41$ to -0.25$)$ \\
\hline $40-$ & 36 & 30.6 & 16.7 & 19.4 & 8.3 & (1.8 to 22.5 ) & -0.03 & $(-0.30$ to 0.23$)$ & -0.26 & $(-0.55$ to -0.04$)$ \\
\hline \multicolumn{11}{|l|}{ Education } \\
\hline Junior high school & 106 & 69.8 & 34.9 & 37.7 & 6.6 & (2.7 to 13.1$)$ & 0.03 & $(-0.13$ to 0.20$)$ & -0.47 & $(-0.69$ to -0.24$)$ \\
\hline Senior high school & 702 & 40.2 & 17.2 & 18.2 & 5.4 & (3.9 to 7.4 ) & 0.07 & ( 0.01 to 0.14 ) & -0.34 & $(-0.42$ to -0.25$)$ \\
\hline Vocational school & 190 & 45.8 & 12.1 & 15.8 & 7.4 & (4.1 to 12.1 ) & -0.06 & $(-0.18$ to 0.07$)$ & -0.48 & $(-0.64$ to -0.33$)$ \\
\hline Junior college & 131 & 16.0 & 7.6 & 6.9 & 5.3 & (2.2 to 10.7 ) & 0.14 & $(-0.01$ to 0.29$)$ & -0.22 & $(-0.37$ to -0.07$)$ \\
\hline College/university and higher & 40 & 10.0 & 5.0 & 5.0 & 7.5 & (1.6 to 20.4$)$ & -0.01 & $(-0.26$ to 0.24$)$ & -0.10 & $(-0.44$ to 0.24$)$ \\
\hline \multicolumn{11}{|l|}{ Occupation } \\
\hline Self-employed & 250 & 29.2 & 13.6 & 14.0 & 5.6 & (3.1 to 9.2 ) & -0.03 & $(-0.14$ to 0.07$)$ & -0.45 & $(-0.58$ to -0.32$)$ \\
\hline Employed (full-time) & 86 & 52.3 & 18.6 & 19.8 & 7.0 & (2.6 to 14.6 ) & -0.04 & $(-0.23$ to 0.14$)$ & -0.45 & $(-0.64$ to -0.26$)$ \\
\hline Employed (part-time) & 103 & 62.1 & 30.1 & 34.0 & 6.8 & (2.8 to 13.5 ) & 0.15 & (-0.03 to 0.33$)$ & -0.29 & $(-0.52$ to -0.07$)$ \\
\hline Housewife & 704 & 39.2 & 15.3 & 16.6 & 5.7 & (4.1 to 7.7 ) & 0.08 & ( 0.02 to 0.15$)$ & -0.31 & ( -0.39 to -0.22$)$ \\
\hline
\end{tabular}

Total number may differ for each demographic characteristic because of missing values. 
Table 2. Risk of preterm birth according to maternal smoking by trimester.

\begin{tabular}{|c|c|c|c|c|c|c|}
\hline Smoking by trimester & No. of mothers & $\begin{array}{c}\text { No. of } \\
\text { preterm births }\end{array}$ & Odd ratio & ( 95\%CI ) & $\mathrm{P}$ & $\begin{array}{c}\text { Mean no. of } \\
\text { cigarettes/day }\end{array}$ \\
\hline Non-smoker & 716 & 28 & 1.0 & referent group & & 0 \\
\hline Smoked first trimester only & 250 & 20 & 2.1 & (1.2 to 3.9$)$ & 0.0167 & 11.5 \\
\hline Smoked first and second trimesters only & 14 & 0 & 0.0 & ) & - & 12.1 \\
\hline $\begin{array}{l}\text { Smoked first and third trimesters, } \\
\text { second and third trimesters or } \\
\text { third trimester only }\end{array}$ & 31 & 5 & 4.7 & (1.7 to 13.2 ) & 0.0052 & 7.9 \\
\hline Smoked throughout & 183 & 15 & 2.2 & (1.1 to 4.2$)$ & 0.0257 & 10.2 \\
\hline
\end{tabular}

Estimates for mothers who smoked during the first trimester only and those who smoked during the first and second trimesters only were based on the number of cigarettes/day smoked during the first trimester.

Estimates for mothers who smoked during the first and third trimesters, the second and third trimesters or the third trimester only, and those who smoked throughout pregnancy were based on the number of cigarettes/day smoked during the third trimester.

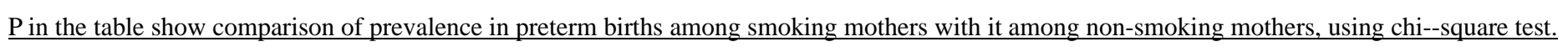


Table 3. Z scores for weight and body length of neonate according to maternal smoking by trimester.

\begin{tabular}{|c|c|c|c|c|c|c|c|c|c|}
\hline \multirow[t]{2}{*}{ Smoking by trimester } & \multirow[t]{2}{*}{ No. of mothers } & \multicolumn{4}{|c|}{ Z score for weight } & \multicolumn{4}{|c|}{ Z score for body length } \\
\hline & & mean & ( 95\%CI ) & $\mathrm{P} 1$ & $\mathrm{P} 2$ & mean & ( 95\%CI ) & P1 & $\mathrm{P} 2$ \\
\hline Non-smoker & 716 & 0.11 & (0.05 to 0.18$)$ & & & -0.30 & $(-0.38$ to -0.21$)$ & & \\
\hline Smoked first trimester only & 250 & 0.07 & $(-0.04$ to 0.19$)$ & 0.5280 & & -0.33 & $(-0.45$ to -0.20$)$ & 0.6890 & \\
\hline Smoked first and second trimesters only & 14 & -0.44 & $(-1.02$ to 0.15$)$ & 0.0260 & 0.0435 & -0.20 & $(-0.80$ to 0.33$)$ & 0.8346 & 0.7499 \\
\hline $\begin{array}{l}\text { Smoked first and third trimesters, } \\
\text { second and third trimesters } \\
\text { or third trimester only }\end{array}$ & 31 & -0.08 & $(-0.39$ to 0.23$)$ & 0.2527 & 0.3906 & -0.31 & $(-0.68$ to 0.07$)$ & 09576 & 0.9191 \\
\hline Smoked throughout & 183 & -0.19 & $(-0.33$ to -0.06$)$ & $<0.0001$ & 0.0034 & -0.63 & $(-0.78$ to -0.47$)$ & 0.0003 & 0.0056 \\
\hline
\end{tabular}

One-way analysis of variance followed by two-tailed Bonferroni/Dunn's technique was used to compare with non-smoking mothers (P1) and mothers who smoked during the first trimester only (P2). 
(2)
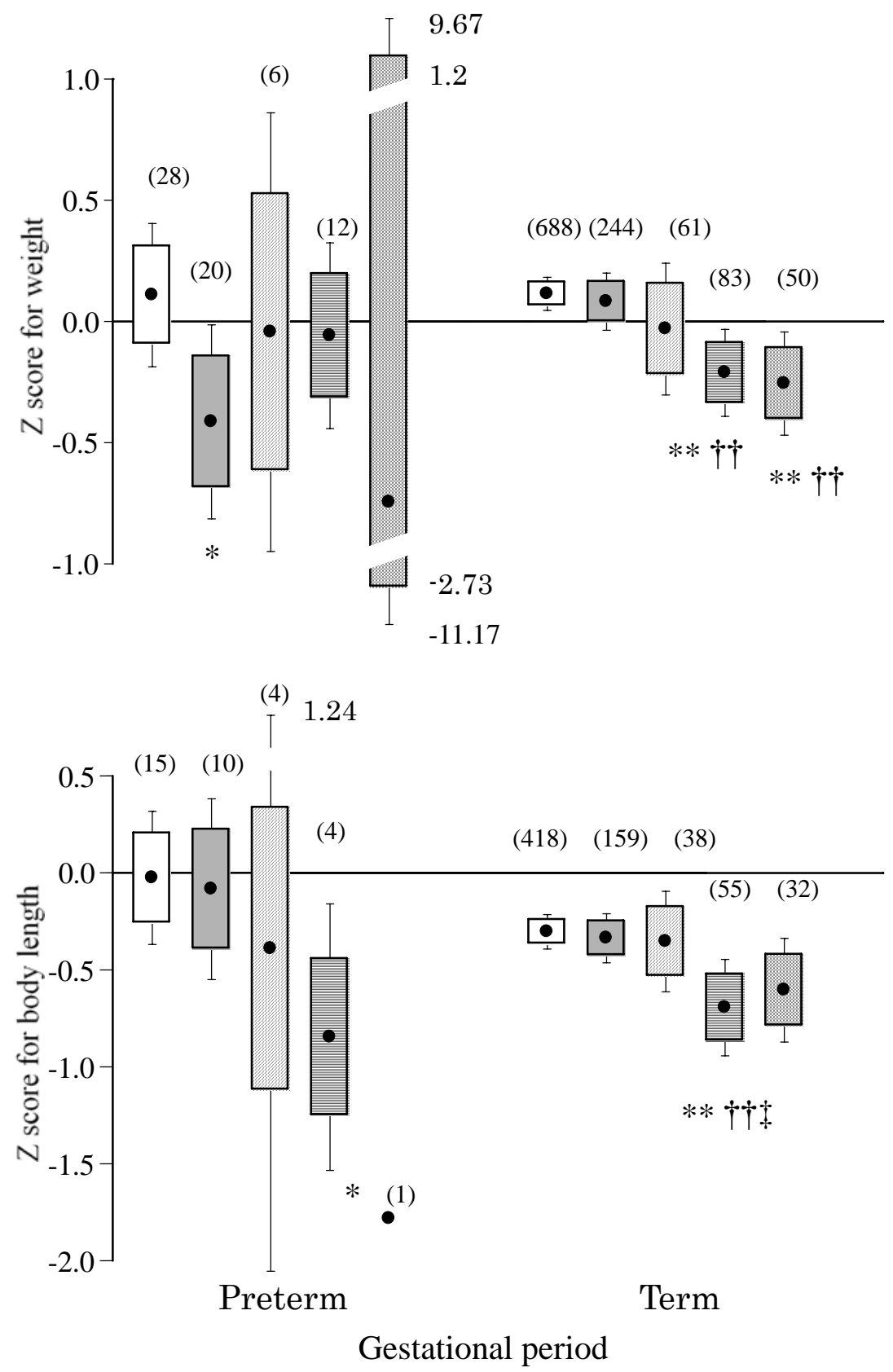

Non-smoker

Smoked during first and/or second trimesters only

Smoked during third trimester: 1-5 cigarettes/day
Smoked during third trimester: 6-10 cigarettes/day

Smoked during third trimester: over 11 cigarettes/day 